\title{
ВЛИЯНИЕ ФАКТОРОВ РИСКА НА ПАРАМЕТРЫ ЭКОНОМИЧЕСКОГО МОДЕЛИРОВАНИЯ ЭФФЕКТИВНОСТИ РАЗРАБОТКИ НЕФТЯНЫХ МЕСТОРОЖДЕНИЙ
}

\author{
(c) 2020 Лебедев Алексей Сергеевич \\ Тюменский индустриальный университет, Россия, Тюмень \\ E-mail: dacent.tmn@gmail.com
}

\begin{abstract}
Проанализирована среда неопределенности и риска разработки нефтяного месторождения, рассмотрены основные факторы нестабильности внешней и внутренней среды реализации проекта выявлены входные параметры экономической модели оценки эффективности разработки месторождения, на которые указанные факторы влияют. Параметры могут быть использованы при оценке проекта с учетом риска.
\end{abstract}

Ключевые слова: риск, неопределенность, экономическая эффективность, разработка месторождения, экономическое моделирование, инвестиции, инвестиционный проект

Разработка и внедрение инвестиционных проектов в нефтегазодобывающем производстве происходит в условиях быстро изменяющейся внешней среды. Кроме того, специфические особенности отрасли накладывает значительную условность на информационную базу и технологические данные любого проекта. Особенно это характерно для инвестиционных проектов, связанных с освоением малоизученных объектов. Поэтому моделирование финансово-экономических результатов и экономический анализ проектов носят нечёткий характер. В таких условиях принятие адекватных инвестиционных решений требует достаточно глубокой проработки вопросов учёта риска и неопределённости при анализе проекта.

Первым этапом управления риском (рис.1) является его качественная оценка, то есть анализ среды неопределённости, риска $[6,7,8]$. В общем смысле этого термина риск определяется как опасность, возможность убытка или ущерба. Другими словами, риск относится к возможности наступления какого-либо неблагоприятного события.

Прежде чем говорить о факторах риска, неопределенности и методических основах их оценки, следует определиться с терминологией, так как в зависимости от источника данные понятия трактуются по-разному. Автор придерживается классической позиции Ф.Найта, предполагающей следующее разграничение категорий «риск» И «неопределенность» [9].

В рамках указанной позиции, под риском чаще всего понимают вероятность возможных потерь части ресурсов, недополучения доходов, появления дополнительных расходов по сравнению с вариантом, предусмотренным проектом, или дисперсию вокруг предполагаемого результата. Средой риска в этом случае является ситуация, когда известны возможные исходы осуществления проекта и статистические характеристики (вероятности) их появления.

Среда неопределенности соответствует такой ситуации, когда известны только возможные исходы реализации проекта и неизвестны вероятности этих исходов.

Все риски, которые возникают при реализации проекта разработки нефтяного месторождения, можно подразделить на несколько видов: риски, присущие любым проектам, независимо от их отраслевой принадлежности - политический, социальный, финансовый, технический, производственный, инновационный, экологический, юридический, а также группу специфических отраслевых рисков (рис.2).

Политический риск - риск несения убытков или недополучения финансовых результатов вследствие изменений в государственной внешней или внутренней политике. Политический риск обусловлен вероятными преобразованиями курса правительства, в частности изменениями фискальных, налоговых условий, денежнокредитной политики, формировании новых контрольно-ревизионных органов, функций и т.д. Данный вид риска влияет на изменение таких параметров проекта, как величина налоговых отчислений, ставки дисконтирования, условий банковского кредитования проектов (если 


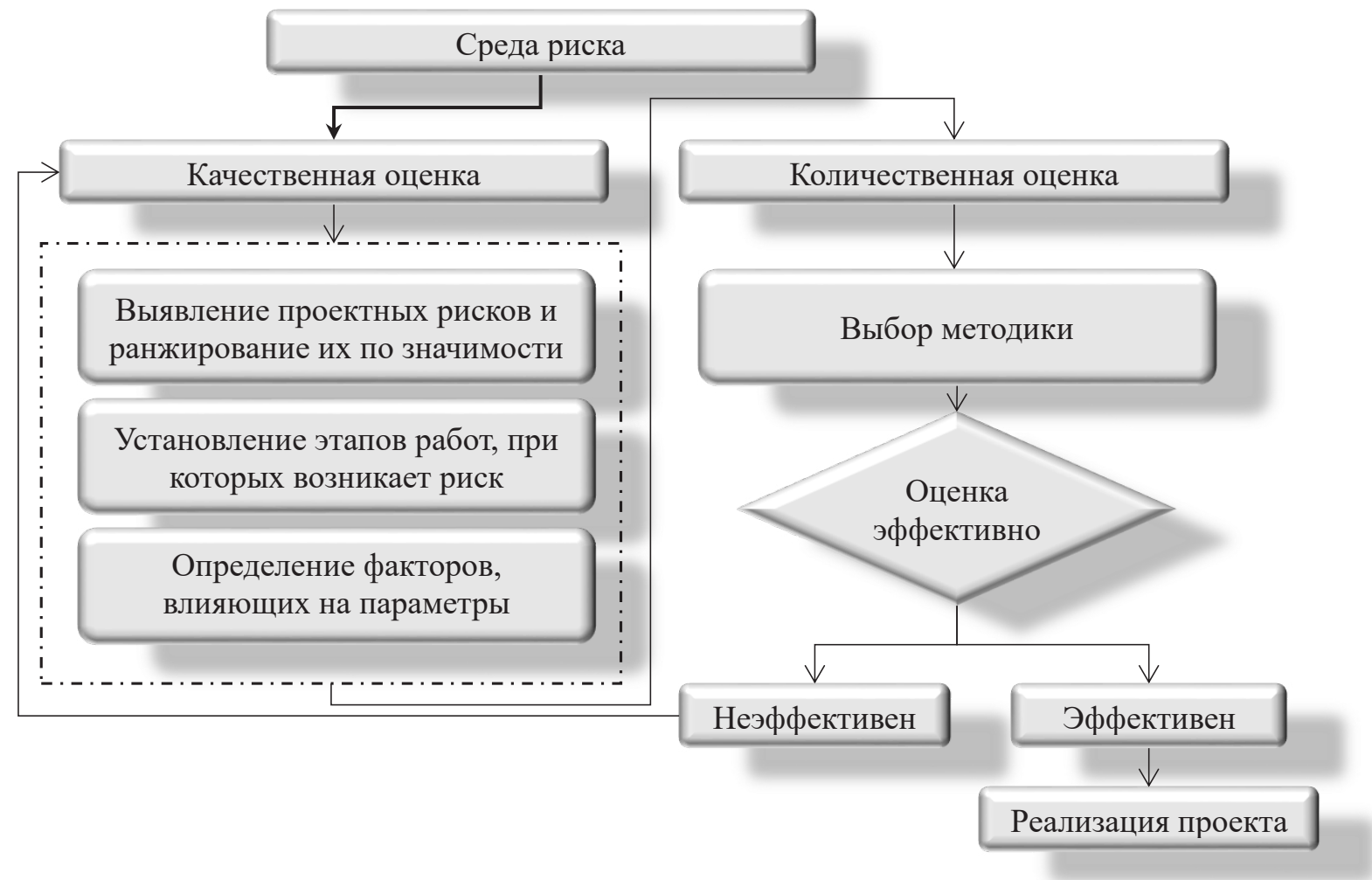

Рис.1. Принципиальная последовательность анализа проектов с учетом риска

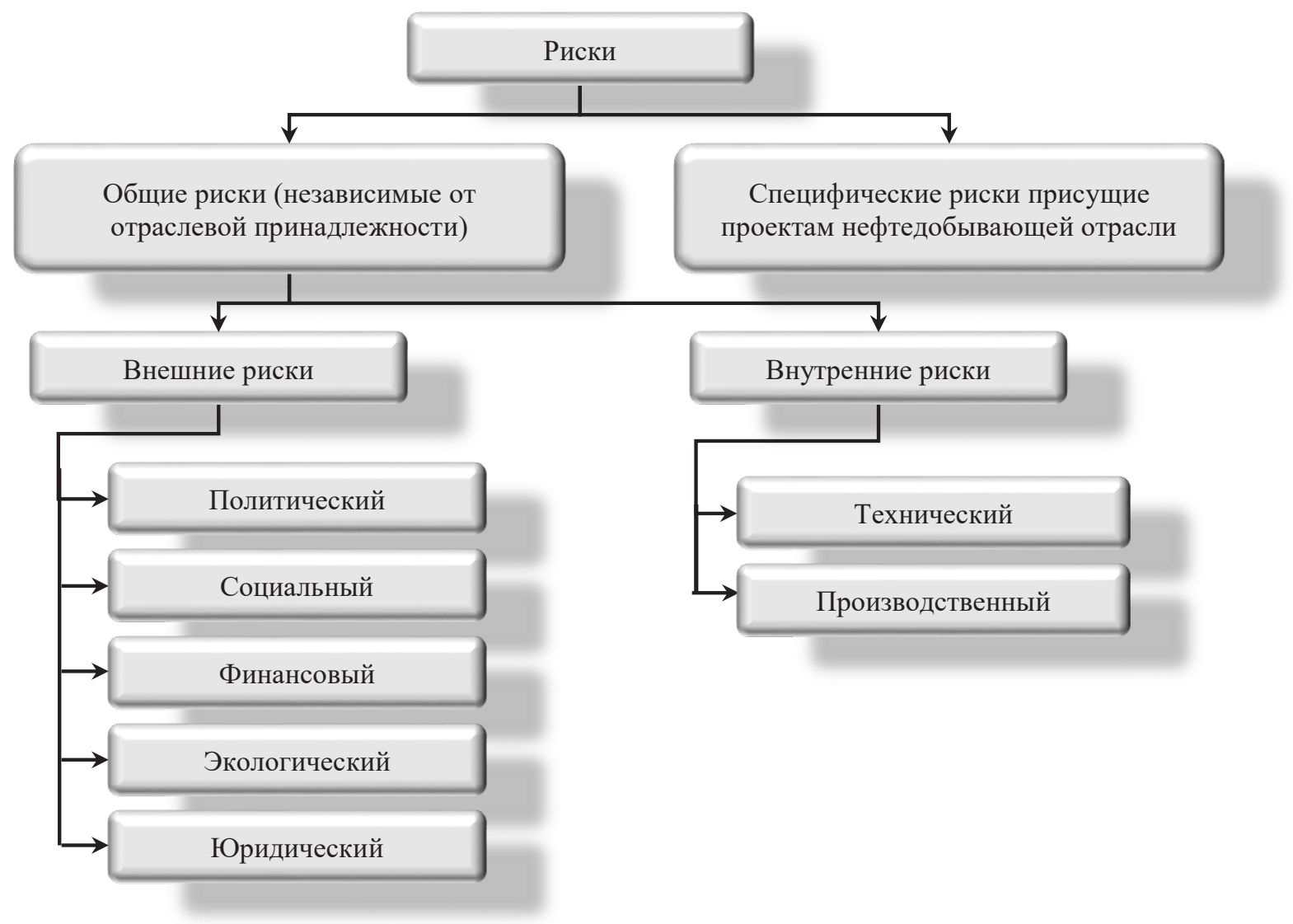


моделирование выполняется с использованием заемных средств).

Социальные риски, под которыми подразумеваются возможности формирования таких негативных социальных явлений как ухудшение криминогенной обстановки, безработица, вероятность забастовок, протестов, демонстраций, массовых беспорядков, недоверие со стороны персонала, как органам власти, так и администрации предприятия. Последствия данных явлений будут выражены в увеличении эксплуатационных затрат на реализацию проекта за счет роста заработной платы, увеличения страховых расходов, а также затрат на системы безопасности.

Финансовый риск - это риск, возникающий в процессе осуществлении финансовой деятельности предприятия, обусловленный тем, что в финансовом секторе в качестве товара выступают валюта, ценные бумаги, либо денежные средства, а также финансовые услуги. Данный вид риска обуславливает, как правило изменение цен реализации продукции проекта, курса валюты, условий кредитования проекта.

Технический риск. Рациональная деятельность предприятия, как правило, связана с внедрением новой или модернизацией действующей техники, повышением техникотехнологической эффективности производства. Однако внедрение новой техники и технологии приводит к возможности аварий, причиняющих значительный ущерб окружающей среде, персоналу и деятельности предприятия в целом. Технический риск обуславливается уровнем организации производства, реализацией необходимых мероприятий (регулярной диагностики, профилактического ремонта и иных мер безопасности). Данные риски могут приводить к росту капитальных вложений и эксплуатационных затрат, ввиду удорожания техники, оборудования и необходимости их ремонтов.

Производственный риск связан с производством продукции, выполнением работ и оказанием услуг, с осуществлением каких-либо видов производственной деятельности, в процессе которой предприятие может сталкиваться с возможностью нерационального использования сырья, полуфабрикатов, что приводит к росту себестоимости, увеличению потерь затрат рабочего времени, использованию нестандартных методов производства. Факторы, обусловленные производственным риском чаще всего оказывают влияние на величину эксплуатационных из- держек.

Экологический риск обусловлен вероятным возникновением природных катаклизмов (землетрясений, наводнений, цунами, ураганов и т.д.), пожаров, аварий и т.д. Ввиду возникновения ситуаций, связанных с экологическим риском, могут возникать дополнительные затраты, как на стадии строительства промысловых объектов, так и в процессе эксплуатации месторождения.

Юридический риск обуславливается негативными для участников разработки месторождения изменениями в законодательстве (появлением новых налогов, повышение ставок по существующим платежам, отмена налоговых послаблений, введение дополнительных контрольных функций и т.д.). Данный риск, как правило, связан с увеличением налоговой нагрузки.

Отраслевые особенности нефтедобывающего производства оказывают влияние и на формирование системы проектных рисков. Для инвестиционных проектов в этой отрасли характерны все вышеописанные риски. Наряду с ними специфическими для нефтедобычи являются: риск неоткрытия месторождения; риск открытия нерентабельного месторождения; риск, связанный с неточным определением геолого-промысловых характеристик объекта разработки (объема геологических запасов, уровня нефтегазоизвлечения, объема извлекаемых запасов, динамики добычи углеводородов и т.д.); риск, связанный с завершением проекта; риск, связанный с условиями рынка сбыта нефти; риск, обусловленный качествами участников проекта; риск, вызванный повышенной вероятностью возникновения форс-мажорных ситуаций $[1,5,6]$.

Таким образом, краткое рассмотрение факторов риска позволяют выявить основные входные параметры финансово-экономической модели проекта разработки нефтяного месторождения, которые следует в дальнейшем использовать при реализации методических подходов к оценке экономической эффективности с учетом нестабильности внешней и внутренней среды реализации проекта. В качестве таких параметров авторы считают целесообразным рассматривать объемы добываемой нефти, цены реализации нефти на внешних и внутренних рынках, уровень капитальных и эксплуатационных расходов на реализацию проекта, величину налоговой нагрузки и норму дисконта. 


\section{Библиографический список}

1. Андреев А.Ф., Дунаев В.Ф., Зубарева В.Д., ИваникВ.В., Иванов А.В., Кудинов Ю.С., Пономарёв В.А., Саркисов А. С. Основы проектного анализа в нефтяной и газовой промышленности.- М., 1997. - 341 с.

2. Балдин К. В., Воробъев С.Н. Риск - менеджмент.- М.: Гардарики, 2005.-285с.

3. Васин С. М. Управление рисками на предприятии: учебное пособие / С. М. Васин, В.С.Шутов.- М.: КНОРУС, 2010. 304c.

4. Воронцовский, А.В. Оценка рисков: учебник и практикум для бакалавриата и магистратуры / А. В.Воронцовский.-М.: Издательство Юрайт, 2019.- 179 с.

5. Захаров Е.В., Ампилов Ю.П. Сравнительная оценка геологического и инвестиционного рисков на начальном этапе изучения месторождений углеводородов. // Нефть, газ и бизнес. - 2001. - № 2. - c. 73-76.

6. Лебедев А.С., Плёнкина В.В. Управление сырьевым потенциалом нефтедобывающего производства в условиях нестабильной среды // Известия высших учебных заведений. Нефть и газ, 2001. - № 5. - c. 120-127.

7. Основы риск-менеджмента / Д.Гэлаи, М.Кроуи, В.Б. Минасян, Р.Марк.- М.: Издательство Юрайт, 2019.390 с.

8. Фомичев А.Н. Риск-менеджмент: Учебное пособие.- М.: Издательско-торговая корпорация «Дашков и К», 2004.- 292c.

9. Фрэнк Хейнеман Найт. Риск, неопределенность и прибыль. - М.: Дело, 2003. - 360 с.

10. Чернова Г.В., Кудрявцев А. А. Управление рисками: учеб. пособие.- М.: Проспект, 2009.-160с. 